\title{
An Acquisitionist's Perspective to Teaching Introductory Linguistics
}

\author{
John M. Ryan \\ Department of Hispanic Studies, University of Northern Colorado, Greeley, USA
}

\begin{abstract}
This paper offers the perspective of an acquisitionist for teaching in an introductory linguistics course, the topics corresponding to the more structural component systems or levels of language, namely, phonetics, phonology, morphology, and syntax. Many introductory linguistics textbooks are far too advanced and contain too much information for undergraduate students to grasp within the short period of time customarily allotted in a three-credit course. In fact, it is quite common for instructors to have to pick and choose the information they are going to cover, many times resorting to skipping entire chapters and major concepts that are basic to the linguistic enterprise. Even when comprehensive coverage is attempted, students are often left with little or no time to absorb the necessary concepts within each unit for later application when discussing more specific areas that students find most interesting and relevant such as historical or dialectal differences in the language(s) they are studying. It is argued that approaching these basic components as different steps in the process of acquiring one's L1(s) impresses upon students and provides them with an appreciation for (1) the individuality of each system; (2) the integration among systems (e.g., the difference between phonetics and phonology is easier to remember if one thinks as the former as the earlier infant-stage of perception and articulation and the latter as the eventual organization of rules in a system); (3) how children learn their first language(s); and (4) more generally, the nature and power of the human capacity for language.
\end{abstract}

Index Terms - teaching linguistics, language acquisition, human capacity for language

\section{INTRODUCTION}

Linguistics as a science covers a wide range of possible areas of investigation, areas that include the more fundamental structural components of language such as phonetics, phonology, morphology, and syntax, as well as topicspecific areas such as synchronic or diachronic variation in language, language acquisition, the communicative efforts of animals, to only name a few. In an effort to let no stone go unturned, introductory linguistics textbooks such as that by Fromkin et al. (2013), now in its ninth edition, try to squeeze this daunting variety into one semester. The problem I see with this approach is that it is overly ambitious, unrealistic, and in the end, defeats its original purpose of inclusiveness, leaving students with a feeling that they have been overexposed and not having a good handle on even the most basic of areas.

One area that frequently gets overlooked in the grand endeavor of an introductory course is perhaps one of the most basic to our enterprise, and that is the human capacity to acquire, create, and understand language in the first place. This, in the opinion of the author, is perhaps one of the biggest oversights among many of the current introductory textbooks on the market. A case in point is the text by Azevedo (2008), now in its $3^{\text {rd }}$ edition, which specializes in Spanish linguistics. Although the book is quite comprehensive in terms of topics specifically related to Spanish such as variation in all its possible forms, what lacks is a section in any of the chapters on the nature and power of language and how it is that we acquire it.

One cannot help but wonder whether approaching linguistics from this new perspective might even help change the general common misconception among the general populace, including the college-educated, about the nature of what linguists do. Most of us have stopped counting the number of times when people immediately ask after learning that we are linguists just how many languages we speak. It is not the fault of the person who asks, of course. In fact, it is symptomatic of the general tendency to take for granted the importance of this fundamental capacity that we all have as humans to use language, and ironically, even among introductory linguistic textbook writers. What's even more ironic is the fact that we use our basic capacity for language to create these textbooks, write articles, learn other languages, get our degrees, and so on, and so this is an area that this author feels is high time to bring back up to the top.

The reasons for this approach are many. Aside from the important fact that L1 acquisition is the author's area of expertise, if one stops to think about it, our human capacity to learn, understand, and produce language is also the most basic. Without our capacity for language, there would not be any need to explain the rest because they would not exist, no dialects, no language change over time, no anything! Teaching linguistics in this manner is also an opportunity to make students think abstractly and critically, outside the box of their language. The author often tells students at the outset of his courses to expect to leave their language at the door, that we are going to try to approach the different component areas of language as if we have never been exposed to any language before. The purpose of doing this is to 
give students an appreciation for the language-learning task and, in the process, to also impress on them how language works in general.

Finally, many are the advantages to presenting the fundamental structural components to language from the perspective of L1 acquisition. In the first place, our language learning capacity serves as a centralizing theme around which the different structural components can be organized. In this way, components can first be shown to exist as individual systems with their own rules, and at some later stage of development, as systems which function in relation to each other. This, in turn, implies both the complexity of language and how it works in general. The following section of this paper proceeds to explain in greater detail how this approach has worked in the author's introductory linguistics classroom.

\section{DISCUSSION}

At the beginning of this paper it was mentioned that one of the first things the author asks students to do in order to get them to think abstractly is to attempt to leave the knowledge they already have of their L1(s) at the door. One of the reasons for doing this is to put the student in the position of the child in an effort to reinforce the individual complexity of each of the component systems of language. At first, students have to be reminded repeatedly to think in terms of only one particular system, and this always starts out as a challenge because, as we will see later in this paper, the component systems normally work together, but eventually, after a few examples, students do finally understand what this means. A real example of this challenge from the author's classroom is the student's initial tendency to think of phones in terms of letters of the alphabet as opposed to sounds. Another example is the idea that words themselves are the smallest units of meaning for no other reason than these are the components that they are used to dealing with when they think about language, if they ever do. When I ask these same students to approach these systems as an infant would, they begin to see more clearly that letters of the alphabet are no longer relevant because a child does not know what these are. At this point, students can then truly begin to focus on sounds and not letters.

\section{A. Individual Systems}

This section makes some suggestions as to how examples from L1 acquisition can facilitate the explanation of each of the individual structural components of language: (1) phonetics; (2) phonology; (3) morphology; and (4) syntax.

\section{Phonetics and Phonology}

Introductory linguistics textbooks commonly present the difference between phonetics and phonology as that between (1) a simple inventory of sounds and their articulation (phonetics) and (2) a more complex system with rules (phonology). What the author of this paper has found is that by presenting each of these areas with concrete examples from L1 acquisition, the differences between them become clearer and much easier for the student to remember.

Research in the area of L1 acquisition has concluded that a healthy child has the capacity of learning any language(s) to which he or she has interactive exposure. The process of learning language begins at birth, the first step being categorization of the totality of individual sounds in a particular language. This first juncture is critical because no other, more advanced language learning (i.e., at the phonological, morphological, or syntactic level) can take place until the child can recognize the particular sounds of the target language and how these are combined at these other levels.

Mastery at the phonetic stage of language acquisition includes both receptive and productive skills, however, the latter, of course, takes much longer to master as it must also align with both mental and physical development of the child. After all, certain sounds, although they are understood by infants early on, just cannot be produced because they are dependent on the development of the teeth or additional control of the muscles in the tongue or jaw. For example, research has found that cross-linguistically, liquids are typically difficult to articulate, and therefore some of the last, sounds to be produced by children (e.g., multiple vibrant /r/ in Spanish or the retroflex /r/ in English). It is this initial phase of identification, recognition, and eventual production of the sounds of a language that we can safely tell our students is phonetics.

In contrast, phonology, although related to phonetics in the sense that it too has to do with sounds, is a distinct component from phonetics because it goes beyond the mere identification, recognition, and ability to articulate isolated sounds. It is instead, the second important step in the mastery of the sound system of a particular language to the point where a child can identify how sounds interact together as part of a larger system. After all, the sounds of one's language(s) are not combined in a haphazard fashion, and a child notices that certain similar sounds do not appear randomly (free variation) but rather do appear predictably in the environment of certain other sounds (complementary distribution). One can also introduce to students by means of phonology the notion that language bridges sound with meaning at a much lower level than words, namely, with the mere difference of one sound (minimal pairs). After all, young children know very early on that the difference of only one sound between two words is what gives them different meanings (phonemes) as in the example of fussy versus fuzzy.

\section{Morphology}

After exposing students to both phonetics and phonology, it is common for current textbooks to proceed with the subsequent higher structural level of language, namely, morphology. Morphology is usually defined as that component of language responsible for the structure of words and the assembly of word forms from individual units of meaning. Examples from L1 acquisition can again be employed to explain how morphology works as well. For example, Table 1 
illustrates the order in which 14 basic grammatical morphemes in English were acquired by three young children (i.e., Adam, Eve, and Sarah) according to Brown (1973) ${ }^{1}$ :

TABLE I

ACQUISITION OF BASIC MORPHEMES IN ENGLISH ACCORDING TO BROWN (1973)

\begin{tabular}{|c|c|c|}
\hline English morpheme & Example & Age (in months) \\
\hline 1. -ing & Mommy driving & $19-28$ \\
\hline 2. in & Ball in cup & $27-30$ \\
\hline 3. on & Doggie on sofa & $27-33$ \\
\hline 4. Plural $-s$ & $\begin{array}{l}\text { Kitties eat my ice cream } \\
\text { Forms: } / \mathrm{s} /, / z / \text { and } / \mathrm{iz} / \\
\text { Cats, Dogs, Classes, Wishes }\end{array}$ & $27-33$ \\
\hline 5. Irregular past & Came, Fell, Broke, Sat, Went & $25-46$ \\
\hline 6. Possessive -'s & $\begin{array}{l}\text { Mommy's balloon broke. } \\
\text { Forms: } / \mathrm{s} /, / \mathrm{s} / \text { and } / \mathrm{iz} / \text { as in } \\
\text { regular plural }\end{array}$ & $26-40$ \\
\hline 7. Uncontractible copula & $\begin{array}{l}\text { He is. } \\
\text { (in response to "Who's sick?") }\end{array}$ & $28-46$ \\
\hline 8. Articles & I ses a kitty. & $28-46$ \\
\hline 9. Regular past $-e d$ & $\begin{array}{l}\text { Mommy pulled the wagon } \\
\text { Forms: /d,/t/, /d } \\
\text { Pulled, Walked, Glided }\end{array}$ & $26-48$ \\
\hline 10. Regular $3^{\text {nd }}$ pers. present & $\begin{array}{l}\text { Kathy hits. } \\
\text { Forms: } / 3 /, / z / \text {, and } / \text { iz' }\end{array}$ & $28-50$ \\
\hline 11. Irregular $3^{\text {nd }}$ pers. present & Does, Has & $28-50$ \\
\hline 12. Uncontractible auxiliary & $\begin{array}{l}\text { He is. } \\
\text { (in response to "Who's wearing your hat?") }\end{array}$ & $29-48$ \\
\hline 13. Contractible copula & Man's big. & $29-49$ \\
\hline 14. Contractible auxiliary & Daddv's eating & $30-50$ \\
\hline
\end{tabular}

As Table 1 suggests, Brown's 14 grammatical morphemes can be used to illustrate to students the difference between lexical and grammatical morphemes. It is the author's experience in the classroom that students typically have fewer problems understanding lexical morphemes, most likely because of the real-world referents or concepts that usually correspond to their meaning, especially in the case of free morphemes such as cow. Because students are already used to thinking of words as minimal units of meaning, it is barely a stretch for them to get them to thinking in terms of lexical morphemes. By contrast, grammatical morphemes do not have referents in the world as do their lexical counterparts. Instead, they have purely grammatical meaning as exemplified by such grammatical morphemes as the present participle suffix -ing and the regular past tense suffix - ed. As compared to the lexical variety, these have more abstract or grammatical meaning. Brown's morphemes are useful, real-life examples of the different types of grammatical morphemes, including both those which appear in bound form (like $\underline{-e d}$ or $\underline{-i n g}$ ) as well as those which appear as freestanding words (like in or on), and their usage.

Another advantage to using Brown's morphemes is that, being real examples of children's earliest speech production, they show the usage of morphemes in isolation from others so that students can focus on the particular morpheme. Such is the case of first morpheme acquired -ing and its corresponding example from Brown's data Mommy driving. Early such telescopic examples can draw students' attention to the morpheme being discussed without the clutter or interference of additional morphemes. It has been the author's experience that after a single read-through of Brown's list, students understand more clearly the essence of grammatical morphemes, both free and bound varieties.

\section{Syntax}

Immediately following the presentation of the first three structural levels of phonetics, phonology, and morphology, textbooks then commonly proceed to the next higher, and incidentally, final level of language structure, this being syntax. As such, syntax is usually defined as that component of language that has to do with the structure of phrases and sentences. Put another way, syntax deals with how words are combined in particular sequences and how they relate together in the sentence. In terms of studies of the acquisition of syntax by children, despite the expected disagreement of such particulars as whether a child possesses solely lexical categories from the start and eventually develops functional categories later, as in Radford (1990), or whether a child's syntax is fully present, as in Hyams (1993), all L1 acquisitionists would agree as to some of the basic stages that all children pass through, regardless of the particular language to which they are exposed (Ryan, 2012; Brown, 1973). For example, it has been found universally that within a short window of two years, most children progress from the ability to produce utterances containing one word, to those of two-words, and subsequently to those of three words or more (O'Grady, 1997). This sequence aligns with the generativist claim that the combination of words happens in a successive binary fashion, aptly termed Merge (Chomsky,

\footnotetext{
${ }^{1}$ For those teaching introductory linguistics courses of languages other than English, some careful digging will yield similar studies for other languages such as González (1978) for Spanish or Pierce (1992) for French.
} 
1995). This correlation between the Merge operation in syntax and successive expansion of children's utterances from one to two to three or more words is no mere coincidence and may aid in the explanation of one of the most basic tenets of contemporary generative syntax.

Another observation of the burgeoning syntax of children is a child's early recognition of the target language's word order and the purported application of this knowledge for additional learning. Linguistic typologists classify word order in languages by the relative positions assumed by $\mathrm{S}$ (ubject), $\mathrm{V}(\mathrm{erb})$ and $\mathrm{O}$ (bject) to each other in a simple declarative sentence, resulting in six theoretically possible word orders among the world's languages: (1) SVO; (2) SOV; (3) VOS; (4) VSO; (5) OSV; and (6) OVS, although the first two are the most common, accounting for approximately $75 \%$ of the world's known languages, whereas the last two account for less than 2\% of these same languages (Greenberg, 1966). Just as was seen in the section of this paper on phonetics where it was suggested that children must before anything else first learn to identify the entirety of sounds of the language they are learning, so too they must identify the basic word order structure of their language and how this translates into meaning so that meanings associated with the particular order of words may provide for additional learning as well. This additional learning that has been proposed based on existing syntactic knowledge is a process which has been termed in the field as bootstrapping, and may occur on either semantic grounds as suggested by Pinker (1987) or syntactic grounds according to Hirsh-Pasek, K. \& Golinkov, R. (1999) and Naigles (1990, 1996).

One final example of how a child's acquisition of language can help explain syntax is that of the marking of agreement on the verb in accordance with the head of the subject noun phrase. Take the following examples (1) a. and b.:

(1) a. The toy $\underline{\underline{i s}}$ green.

b. The wings of the toy are green.

If syntax were a question of simple word order and not the result of the interplay of individual phrasal hierarchies, the difference in verb selection in (1) a. and b. would not matter. For example, in a system of simple word order whereby a word immediately preceding the verb determines the verb form, not only (1) a. but (1) b. would also require a single verb form, namely, "is." However, syntax is more hierarchical in nature, and the difference between the verb forms in (1) a. and b. is not determined simply by the word preceding the verb, but rather the head of the noun phrase that precedes the verb.

Although teaching fully the syntactic differences between (1) a. and b. would require an introductory class dedicated entirely to syntax, the simplified version for an introductory linguistics class might consist of limiting the explanation to the difference in structure between the Subject NPs in (1) a. and b. which might be represented by Figures 1 and 2 , respectively:

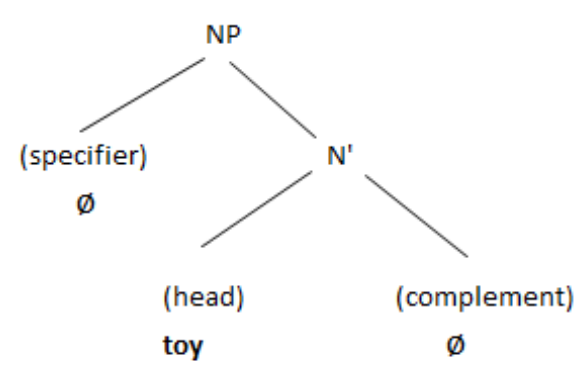

Fig. 1: Syntactic representation of the NP toy

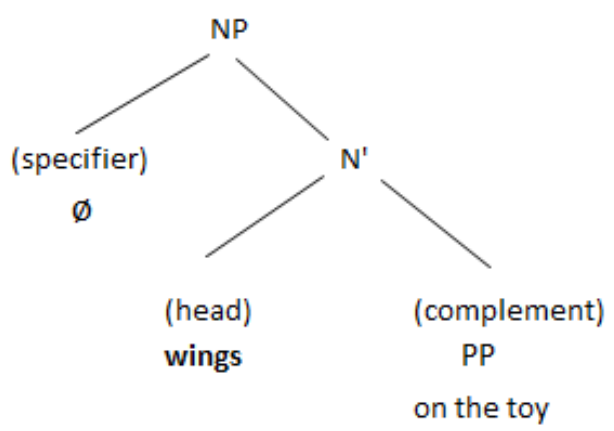

Fig. 2: Syntactic representation of the NP wings on the toy

As illustrated in Figure 1, the head of the noun phrase, in this case toy is singular, hence the singular form of the verb $b e$, or $i s$, is required in the sentence. On the other hand, in Figure 2 the head of the noun phrase wings is plural, therefore, the plural form of $b e$, or are, is required. The advantage of this example can also serve as entree to the explanation of $\mathrm{X}$ - 
Bar Theory and the combination of specifier, head, and complement as the basic components of all phrases, another important assertion of contemporary generative syntax (Chomsky, 1995).

Having illustrated how examples and observations from the field of L1 acquisition can help explain some of the more basic concepts surrounding the individual structural component systems or levels of language, the following section of this paper will now demonstrate how L1 acquisition may also be applied to explain interaction between these same systems or levels.

\section{B. Interrelated Systems}

When it comes to relating the structural systems or levels of language among each other most textbooks indicate the method of presentation of this material from smaller to larger units (sounds to sentences) without mentioning, or even suggesting, that this order happens to be the way in which children acquire these systems. After all, children don't just start producing sentences, but pass through the following particular sequence (give or take 3-6 months for individual differences) which coincidentally corresponds to the order in which textbooks present these topics (in parentheses): (1) by around six months infants are able to recognize and start producing many of the sounds of their target language (which if we were to associate this with one of the systems, it would essentially correspond to phonetics); (2) by around twelve months infants are able to combine certain sounds into meaningful sequences recognizable to a speaker of the target language (corresponding more or less to a textbook's definition of phonology); (3) by around eighteen months infants begin to pretty accurately form words from smaller components (morphology); and (4) between eighteen months and two years infants begin stringing two or more words together in strings of meaningful sequences (syntax).

Rather than attributing to mere chance this uncanny resemblance between the presentation of smaller to larger units and a child's path of acquisition, the author has found that by integrating the two into one explanation actually helps both facilitate and reinforce both areas. To illustrate the power of this approach, the example of the sequence of acquisition of word final sibilants (e.g., [s], [z], and [i z) in English is employed for each of the structural components along the path of first language acquisition.

\section{1st stage (Phonetics)}

At first, all children are continuously exposed to adult English language input and begin to identify all the possible sounds of the language. Children begin to classify [s] and [z] as English sounds and include these as part of their overall inventory. Knowing that these are English sounds, however, does not mean that infants are able to recognize them according to context, in other words, what they are used for in the language.

\section{2nd stage (From Phonetics to Phonology)}

Having now associated $[\mathrm{s}]$ and $[\mathrm{z}]$ as sounds in English, an infant can quickly progress from the initial stage of mere identification of sounds (phonetics) to recognizing that these appear in predictable, and more importantly, meaningful contexts. At this point one may explain to students that infants begin to see the use of sounds as part of an overall system with rules that determine which sounds are used when combined with other particular sounds. For example, children learning English begin to notice that: (1) the unvoiced sibilant [s] appears after a voiceless consonant as in the sequence $c a t+[\mathrm{s}]$, (2) the voiced sibilant [z] appears after a voiced consonant or vowel as in the sequence $d o g+[\mathrm{z}]$ or see $+[\mathrm{z}]$, or (3) the voiced combination [ł z] appears after only certain voiceless consonants as in witch $+[\dot{\mathrm{j}} \mathrm{z}]$.

Consequently, this real-life application of the difference between just plain phonetics and a more robust and complex system of phonology makes for a natural transition to the discussion of the concept of complementary distribution of allophones, which can in turn be contrasted with the notion of free variation. Moreover, this particular illustration with regard to the choice of word final sibilant which is dependent on the preceding sound is a natural segue into an explanation of how the process of assimilation works, and although this case is of the regressive variety, the discussion can be easily expanded to explain the progressive type as well.

At this point, one can also explain to students that the acquisition of the sound "system" involves more than just rules regulating which sounds occur with other sounds but that certain sounds when substituted for each other can also determine the meaning of a word. For example, the two sounds /s/ and /z/ in English when substituted for each other may change the meaning of the words as in the following examples:

(2) a. fuss [s] versus fuzz [z]

b. bus [s] versus buzz [z]

In other words, through these examples it may be explained to students that phonology is also a system that provides for the discriminating ability of some sounds, which in this case are called phonemes, as in $/ \mathrm{s} /$ and $/ \mathrm{z} /$ in English. At this point the concepts of minimal pairs may be introduced as exemplified by (2) a. and $b$.

\section{3rd stage (Integration of Phonology and Morphology)}

As infants begin to make sense of the sounds in the language they are learning (phonology), they also begin to recognize that certain strings of sounds together may also have a unique meaning. Such strings may represent concepts in the real world or they may be even smaller units, oftentimes a single sound that in turn may be pieced together with those strings that correspond to a concept in order to modify the meaning of the concept in a particular way. This other system of assembling parts of words is called morphology and it entails how the individual units of meaning described earlier come together to form words.

It is along these lines that one can further explain to students that morphology is the juncture where sound meets meaning. Returning to our familiar example of word final sibilants, infants learning English begin to notice that the 
sounds $[\mathrm{s}]$ and $[\mathrm{z}]$ are typically used as markers at the end of words to pluralize most singular nouns, according to the phonological rules of regressive assimilation mentioned previously (e.g., cat $+[\mathrm{s}]$; $d o g+[\mathrm{z}]$; and bee $+[\mathrm{z}]$ ) as well as

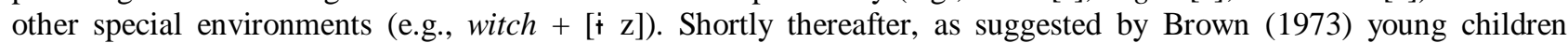
learning English also start noticing that these same sounds [s] and $[\mathrm{z}]$ are also used by adults as word-final markers of genitive case (e.g., Pat $+[\mathrm{s}] ;$ John $+[\mathrm{z}]$ ). Again, the phonological rules of regressive assimilation that applied when adjoining pluralizers to singular nouns can now also be applied when applying the genitive morpheme.

\section{4th stage (Integration of Phonology, Morphology, and Syntax)}

One final example of how the different structural systems interact in terms of the acquisition of word final sibilants is in the phenomenon of the contracted copula, that is 's, in both simple and progressive form. As seen previously, the form of the verb is determined by the head of the noun phrase preceding the verb, such that (1) with the head toy took a singular verb form is and (2) with the head wings took a plural verb form are. A further rule that children must also learn when it comes to the English copula is that the singular form is may either appear in full form or contract with the preceding noun phrase as in (3) a. and b., in both simple present and progressive forms, respectively.

(3) a. The toy's green.

b. The toy's turning green.

In both (3) a. and b., morphological and syntactic operations have taken place to yield agreement between the singular subject and the verb. The contraction of the copula incorporates the level of phonology into the equation whereby assimilation of the regressive type is applied to the word final sibilant just as we have seen that it does for pluralization, formation of the genitive, and third person present tense singular forms. In both (3) a. and b., [z] has been applied because the diphthong [oi] in toy is voiced. If the word were cat, however, [s] would have been the allophone selected.

\section{CONCLUSIONS}

As seen in the preceding sections, certain themes surrounding the structural components or levels of language as they are acquired by children can be used to illustrate how these components function individually as well as in an integrated fashion in the adult target language. The author would argue that presenting the components in such a way has the desirable effect of anchoring students throughout otherwise unconnected units and does so with an underlying theme. Another benefit to this approach is that it introduces the area of first language acquisition in an indirect way rather than trying to find a place for it in the syllabus to be covered as a separate unit. As mentioned at the beginning of this paper, the variety of interesting topics that already compete for coverage in an introductory linguistics course significantly reduce the possibilities of showcasing the acquisition topics suggested throughout the paper. Another advantage to such an approach is that it provides for some flexibility in terms of how much detail within each of the structural components may be presented. For example, although it is the author's personal choice not to include the coverage of phonetic or phonemic transcription when teaching these components in his introductory classroom, the approach itself does not preclude the ability to do that.

Finally, presenting the basic structural components of language through the concepts of language acquisition is a vehicle to demonstrate how language works as a whole. Most introductory linguistics textbooks relegate the concept of UG to part of an overall discussion about the different definitions of the word grammar. The author would argue that the concept becomes not only easier to explain but more meaningful as well when approached in terms of first language acquisition because as students proceed through each of the different levels they are more naturally impressed with the notion of preprogramming of humans for language.

In closing, the author would have to admit that this approach is not for everyone. After all, students of linguistics come in all shapes, sizes, and agendas. Some students are language majors and are used to studying grammar and might find such a course too basic, others who take the course as an elective, however, might find such organization of a class ideal. The idea behind the structure of a class as proposed here is to appeal to a broader audience of students whose purpose of taking introductory linguistics is not to master the International Phonetic Alphabet or become experts in dividing words into their morphological parts. Its goal is much broader and that is to provide a basic understanding and appreciation for the nature and power of human language.

\section{REFERENCES}

[1] Azevedo, M. (2008). Introducción a la lingüística española. (3rd edn.) New Jersey: Prentice Hall.

[2] Brown, R. (1973). A first language: The early stages. Cambridge: Harvard University Press,

[3] Chomsky, N. (1995). The minimalist program (Current Studies in Linguistics). Cambridge: The MIT Press.

[4] Fromkin, V, R. Rodman \& N. Hyams. (2013). An Introduction to Language. (10th edn.) Boston: Wadsworth.

[5] González, G. (1978). The speech of a Chicano child: Spanish grammatical transformations at age 2;6. Paper presented at the SWALLOW Conference, Boulder, CO.

[6] Greenberg, J. (1966). Language universals: With special reference to feature hierarchies. The Hague: Mouton \& Co.

[7] Hirsh-Pasek, K. \& R Golinkoff. (1999). The origins of grammar: Evidence from early language comprehension (Language, Speech, and Communication). Denver: Bradford Publishing.

[8] Hyams, N \& K. Wexler. (1993). On the grammatical basis of null subjects in child language. Linguistic Inquiry 24, 421-59. 
[9] Naigles, L. (1990). Children use syntax to learn verb meanings. Journal of Child Language 17, 357-374.

[10] Naigles, L. (1996). The use of multiple frames in verb learning via syntactic bootstrapping. Cognition 58, $221-251$.

[11] O'Grady, W. (1997). Syntactic development. Chicago: University of Chicago Press.

[12] Pierce, A. (1992). Language acquisition and syntactic theory. A comparative analysis of French and English child grammars. Dordrecht/Boston/London: Kluwer.

[13] Pinker, S. (1987). The Bootstrapping Problem in Language Acquisition. In: MacWhinney, Brian. Ed. Mechanism of Language Acquisition. New Jersey: Laurence Erlbaum Associates.

[14] Radford, A. (1990). Syntactic Theory and the Acquisition of English Syntax. Cambridge: Basil Blackwell.

[15] Ryan, J. (2012). The genesis of argument structure: Observations from a child's early speech production in Spanish. Germany: Lambert.

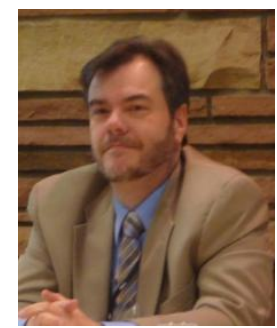

John M. Ryan earned his Ph.D. in Rhetoric, Composition, and Linguistics at Arizona State University in Tempe, Arizona, USA in 2008. He earned his Master's degree in Spanish linguistics, also from Arizona State, in 1991. He earned his Bachelor of Science degree in Spanish from Georgetown University's School of Languages and Linguistics in Washington, D.C. in 1985.

$\mathrm{He}$ is currently Assistant Professor of Spanish Linguistics at the University of Northern Colorado. His research on the acquisition of verbs by children and adults has been published in such journals as the Journal of Child Language Acquisition and Development and Hispania, and his first book, The genesis of argument structure: Observations from a child's early speech production in Spanish (Germany: Lambert, 2012), traces the emergence of the verb phase in the developing language of a monolingual child learning Peninsular Spanish. Other interests include historical news discourse of the Italian American community and the reconstruction of proto Ibero Romance.

Dr. Ryan is a member of the Linguistic Society of America, the Rocky Mountain Modern Language Association, the Linguistic Association of the Southwest, and the Italian American Historical Society. 